\title{
Effects of different cryoprotectants on the cryopreservation of cattle testicular tissue
}

\author{
S. Hu, Q.-C. Zhu, C. Han, X.-G. Zhang, B. Y. Song, D.-Q. Xie, S.-Y. Wei, and J.-H. Hu \\ College of Animal Science and Technology, Northwest A\&F University, Yangling Shaanxi 712100, P.R. China
}

Correspondence to: J.-H. Hu (hjh19732008@126.com)

Received: 17 August 2015 - Revised: 1 November 2015 - Accepted: 6 November 2015 - Published: 26 November 2015

\begin{abstract}
Cryopreservation of testicular tissue is a new option in fertility preservation for prepubertal male animals. The purpose of this study was to explore the effects of different cryoprotectant agents (CPAs) at various concentrations on testes after the cryopreservation of calf testicular tissue. These experiments selected dimethyl sulfoxide (DMSO), glycerol, propylene glycol $(\mathrm{PrOH})$, and sucrose as CPAs in varying doses $(2.5,5,7.5,10$, $12.5,15,17.5$, and $20 \% ; v / v$ ) in 8-month-old calf testicular tissue that was frozen and preserved. Then, cell viability, testosterone production, malondialdehyde (MDA) level, and superoxide dismutase (SOD) level were detected and analyzed following cryopreservation. The results showed that the optimal concentrations of DMSO, $\mathrm{PrOH}$, glycerol, and sucrose were 10,10,7.5, and 10\%, respectively. Compared to the optimal concentrations of CPAs, cell viability and testosterone production decreased significantly at a lower and higher CPA concentration $(P<0.05)$. At the optimal concentrations of CPAs, the DMSO group showed higher cell viability and testosterone production than other CPA groups $(P<0.05)$. Compared to the optimal concentration of CPAs, the MDA level increased and the SOD level decreased at a lower or higher concentration of CPAs, but there was no significant difference $(P>0.05)$. Cell viability was significantly positively correlated with testosterone production $(P<0.05)$. In conclusion, DMSO provided the most effective protection for calf testicular tissue cryopreservation and the optimal concentration was $10 \%$.
\end{abstract}

\section{Introduction}

Currently, the conventional method of the effective preservation of superior livestock breeds and the protection of endangered animal species is the cryopreservation of spermatozoa or reproductive cells. However, the process of cell cryopreservation cannot save testicular tissue cells at all periods, and it may easily cause adverse effects (such as cancer cells) which damage normal cells. Testicular tissue cryopreservation can avoid mechanical damage in the process of cell digestion and reduce the phenomenon of cell hypoxia. This makes the preservation of animal species more efficient (Honaramooz, 2012). By cryopreservation of the collected testis tissues, male fertility could be preserved in the long term and used for further assisted reproduction (Kishikawa et al., 1999; Martinez et al., 2008). The preservation of sperm is not an option for young livestock prior to reaching sexual maturity, but cryopreservation of testis tissue is an emerg- ing fertility preservation strategy before male sexual maturity (Hovatta, 2001; Verheyen et al., 2004; Gosden, 2011).

Although cryopreservation can prolong the survival time of cells or tissues, cryopreservation can produce a large number of reactive oxygen species (ROS) which cause lipid peroxidation (Farias et al., 2010) and lead to cell damage and a decrease in cell viability. Malondialdehyde (MDA) is a decomposition product of lipid peroxidation of the cell membrane. The content of MDA reflects the content of free radicals in the body, and it embodies the degree to which the body is damaged by free radicals (Tatsumi et al., 1997). Superoxide dismutase (SOD), a cellular antioxidant enzyme, plays a key role in the removal of oxygen free radicals in the body and protects cells from damage. The activity of SOD can reflect the ability to remove oxygen free radicals in the body (Chen et al., 2009).

In an animal's body, more than $95 \%$ of testosterone is synthesized and secreted by the Leydig cells. The intact mor- 
phology of Leydig cells and the testicular microhabitat have an important impact on the testosterone level. In healthy male livestock, the synthesis and secretion of testosterone, adjusted by the hypothalamus-pituitary-gonadal axis, leads to stable testosterone levels. In the process of testicular tissue cryopreservation, in vitro procedures and freezing injury can lead directly to mechanical injury to testicular tissue. Testicular tissue is exposed to air, causing oxidative stress, resulting in Leydig cell damage (Cao et al., 2004), and leading to a decrease in the synthesis and secretion of testosterone. After the cryopreservation of testicular tissue, detecting the content of testosterone can be used to evaluate the survival of the tissue (Keros et al., 2007; Curaba et al., 2011; Gouk et al., 2011).

In order to decrease freezing injuries and increase cell viability, cryoprotectant agents (CPAs) have been widely used during the freezing process. CPAs can be divided into two types: permeating and nonpermeating. Dimethyl sulfoxide (DMSO), glycerol, and propylene glycol $(\mathrm{PrOH})$ are permeating CPAs, and sucrose is a nonpermeating CPA. Keros et al. (2005) compared the DMSO and sucrose regarding their testicular tissue cryopreservation effect and showed that $10 \%$ DMSO had the best protection effect and $6 \%$ sucrose had the worst protection effect. DMSO has been found to be a more suitable CPA than ethylene glycol (EG) for immature mouse and rat testis tissue (Goossens et al., 2008; Jezek et al., 2001). Yildiz et al. (2013) indicated that neonatal mouse testes in DMSO had a higher rate of tissue survival than in $\mathrm{PrOH}$ and glycerol after graft.

The cryopreservation of testicular tissue has been reported in humans (Hovatta, 2001; Jahnukainen et al., 2007), mice (Goossens et al., 2008; Milazzo et al., 2008), and swine (Abrishami et al., 2010). However, there is little published information, to our knowledge, on the cryopreservation of testicular tissue in cattle. For the different species, the effects of cryoprotectant on the cryopreservation of testicular tissue could be different, so the study of the cryopreservation of testicular tissue in cattle is necessary. At present, the practical application of this technique in cattle breeding is rare, but with good development of this technology, in the future, it can achieve the long-term preservation of cattle fertility and thus contribute to the breeding and preservation of fine varieties of cattle. In addition, it can protect species diversity. The aim of this study was to test the effects of different CPAs (DMSO, PrOH, glycerol, sucrose) at various concentrations on cell viability, testosterone production, SOD, and MDA of cryopreserved calf testicular tissue.

\section{Materials and methods}

\subsection{Animals}

In the study, the testes $(n=16)$ from eight healthy Qinchuan cattle (8 months) were collected from Qinbao cow farms in Qishan, Shaanxi. The testes were kept in ice-cold phosphatebuffered saline (PBS) supplemented with $5 \%$ penicillin- streptomycin $\left(1000 \mathrm{UmL}^{-1}-1000 \mu \mathrm{g} \mathrm{mL} L^{-1}\right)$ at $37^{\circ} \mathrm{C}$ and transported to the laboratory within $2 \mathrm{~h}$. All animal procedures were approved by the Institutional Animal Care and Use Committee of Northwest A\&F University.

\subsection{Chemical agents}

Unless otherwise stated, all chemicals were purchased from Sigma Chemical Company (St. Louis, MO, USA).

\subsection{Cryopreservation of cattle testicular tissue}

Cryoprotectants were prepared by using Dulbecco's modified Eagle's medium (DMEM) with $20 \%$ fetal bovine serum (FBS) including different CPAs (DMSO, PrOH, glycerol, sucrose) with various volume ratios $(2.5,5,7.5,10,12.5$, $15,17.5$, and $20 \% ; v / v$ ) (Table 1). In addition, DMSO was placed in the refrigerator at $4{ }^{\circ} \mathrm{C}$ before the tissue samples were exposed to DMSO.

The testes were washed three times with PBS, and testis parenchyma was cut into pieces $\left(1-2 \mathrm{~mm}^{3}\right)$ after removing the epididymis, tunica albuginea, rete testis, and overt connective tissue. The pieces were then placed in a $1.8 \mathrm{~mL}$ cryovial containing $1 \mathrm{~mL}$ of different types of cryoprotectants. Then the cryovials were stored at $4{ }^{\circ} \mathrm{C}$ for $2 \mathrm{~h}$ until they reached equilibrium. After this, they were successively stored at $-20^{\circ} \mathrm{C}$ for $2 \mathrm{~h}$ and $-80^{\circ} \mathrm{C}$ for $12 \mathrm{~h}$. Finally, the cryovials were transferred into liquid nitrogen $\left(-196^{\circ} \mathrm{C}\right)$. All experiments were done with three replicates for each treatment group.

\subsection{Thawing of cattle testicular tissue}

After 7 days of cryopreservation, the tissue was thawed in a water bath for about $2 \mathrm{~min}$ at $37^{\circ} \mathrm{C}$ until the ice melted. The cryoprotectant was washed immediately with DMEM supplemented with $20 \%$ FBS, and samples were washed repeatedly.

\subsection{Measurement of cell viability}

Single-cell suspensions that were used to evaluate cell viability were prepared by enzymatic digestion. Cell viability was estimated with Trypan blue dye exclusion. After thawing, testicular tissue fragments were exposed to collagenase $\left(1 \mathrm{mg} \mathrm{mL}{ }^{-1}\right.$ in DMEM) at $37^{\circ} \mathrm{C}$ for $40 \mathrm{~min}$. The suspension was mixed every $5 \mathrm{~min}$, and full enzymatic digestion was performed. The digested suspension was centrifuged at $1000 \mathrm{rpm}$ for $5 \mathrm{~min}$ and the supernatant discarded. Then the suspension was digested by $0.25 \%$ trypsin with $5 \% \mathrm{CO}_{2}$ in air at $37^{\circ} \mathrm{C}$ for $10 \mathrm{~min}$. Trypsin digestion was stopped by adding a $10 \%$ FBS solution, and the cell suspension was filtered through a 400 mesh cell strainer; incompletely digested tissue was removed. The filtrate was centrifuged at $1000 \mathrm{rpm}$ for $5 \mathrm{~min}$, the supernatant discarded, and the pellet resuspended in incomplete DMEM. A unicellular suspension was 
Table 1. The components of different cryoprotectants (volume ratio).

\begin{tabular}{llrrrrrrrr}
\hline Components $^{1}$ & 1 & 2 & 3 & 4 & 5 & 6 & 7 & 8 \\
\hline & DMSO & & & & & & & & \\
CPAs $^{2}$ & Glycerol & $2.5 \%$ & $5 \%$ & $7.5 \%$ & $10 \%$ & $12.5 \%$ & $15 \%$ & $17.5 \%$ & $20 \%$ \\
& PrOH & & & & & & & & \\
& Sucrose & & & & & & & & \\
\hline \multirow{2}{*}{ Medium } & FBS & $20 \%$ & $20 \%$ & $20 \%$ & $20 \%$ & $20 \%$ & $20 \%$ & $20 \%$ & $20 \%$ \\
& DMEM & $77.5 \%$ & $75 \%$ & $72.5 \%$ & $70 \%$ & $67.5 \%$ & $65 \%$ & $62.5 \%$ & $60 \%$ \\
\hline
\end{tabular}

\footnotetext{
${ }^{1}$ CPAs: cryoprotectant agents; DMSO: dimethyl sulfoxide; PrOH: propylene glycol; FBS: fetal bovine serum; DMEM: Dulbecco's modified Eagle's medium.

${ }^{2}$ DMSO, glycerol, $\mathrm{PrOH}$ and sucrose were added to medium.

${ }^{3}$ The concentration of sucrose is $0.04 \mathrm{~g} \mathrm{~mL}^{-1}$.
}

obtained, was diluted to $1 \times 10^{6}$ cells $\mathrm{mL}^{-1}$, and mixed with $0.4 \%$ trypan blue solution in a ratio of $9: 1$. Each treatment was repeated three times.

\subsection{Frozen-thawed testicular tissue culture}

After thawing, testis fragments were cultured in a culture dish for $24 \mathrm{~h}$ at $34^{\circ} \mathrm{C}$ in a humidified atmosphere with $5 \%$ $\mathrm{CO}_{2}$ in the air. The culture media used were DMEM-F12 supplemented with $10 \% \mathrm{FBS}, 50 \mathrm{U} \mathrm{mL}^{-1}$ penicillin, and $50 \mathrm{mg} \mathrm{mL}^{-1}$ streptomycin, and the tissue was kept at the gasliquid interphase. Cultured tissue was used for later biochemical assays.

\subsection{Biochemical assays}

After spending 1 day in the culture, $10 \%$ testicular tissue homogenates were prepared using the following method. Testicular tissue samples were centrifuged at $1000 \mathrm{rpm}$ for 5 min, and the CPAs were discarded. Then tissue samples were homogenized in PBS (testis : total buffer ratio is $1: 10$ ) for $5 \mathrm{~min}$. After the homogenate was centrifuged at $2000 \mathrm{rpm}$ for $10 \mathrm{~min}$ at $4{ }^{\circ} \mathrm{C}$, the supernatant was obtained and stored at $-20^{\circ} \mathrm{C}$ for biochemical assays. The content of MDA, the activity of SOD, and testosterone production were detected and analyzed following cryopreservation.

\subsubsection{Measurement of testosterone production}

Concentrations of testosterone in the culture media were determined by direct immunoassay with the use of an ELISA kit (Diagnostic Systems Laboratories, Inc., Webster, TX) according to the manufacturer's instructions. The standard curve was prepared from the absorbance readings, and the testosterone concentrations of each sample were determined. Each treatment was repeated three times.

\subsubsection{MDA}

The level of MDA was measured by thiobarbituric acid (TBA). An MDA testing kit (Nanjing Jiancheng Bioengi- neering Institute, Zhongyang Road, Nanjing) was used. In accordance with the instructions of the kit, MDA content was measured at $532 \mathrm{~nm}$ on the spectrophotometer and expressed as nanomole per milligram.

\subsubsection{SOD}

The activity of SOD was determined by xanthine oxidase; an SOD assay kit (Nanjing Jiancheng Bioengineering Institute, Zhongyang Road, Nanjing) was used. In accordance with the instructions of the kit, SOD activity was measured at $560 \mathrm{~nm}$ on the spectrophotometer and expressed as U/mg per milligram.

\subsection{Statistical analyses}

SPSS Statistics 17.0 (SPSS Inc., Chicago, IL, USA) was used for the data analysis. The effects of different CPAs on cell viability, testosterone, MDA, and SOD level were analyzed with a one-way analysis of variance (ANOVA). Pearson's correlation coefficient $(r)$ with $P$ value was used to determine correlation between cell viability, on the one hand, and testosterone production, MDA, and SOD level on the other. Values were given as mean $\pm \mathrm{SE}$, and $P<0.05$ was considered statistically significant.

\section{Results}

\subsection{The effects of different CPAs on cell viability and testosterone production}

As shown in Fig. 1, after the cryopreservation of calf testicular tissue, cell viability and testosterone production were significantly lower than in fresh testicular tissue, and they were significantly affected by the CPA types and concentrations $(P<0.05)$. The optimal concentration of DMSO, $\mathrm{PrOH}$, glycerol, and sucrose was 10,10, 7.5, and $10 \%(P<0.05)$, respectively. Cell viability and testosterone production decreased significantly at a lower concentration of CPAs, compared to levels at the optimal concentration, as well as at 

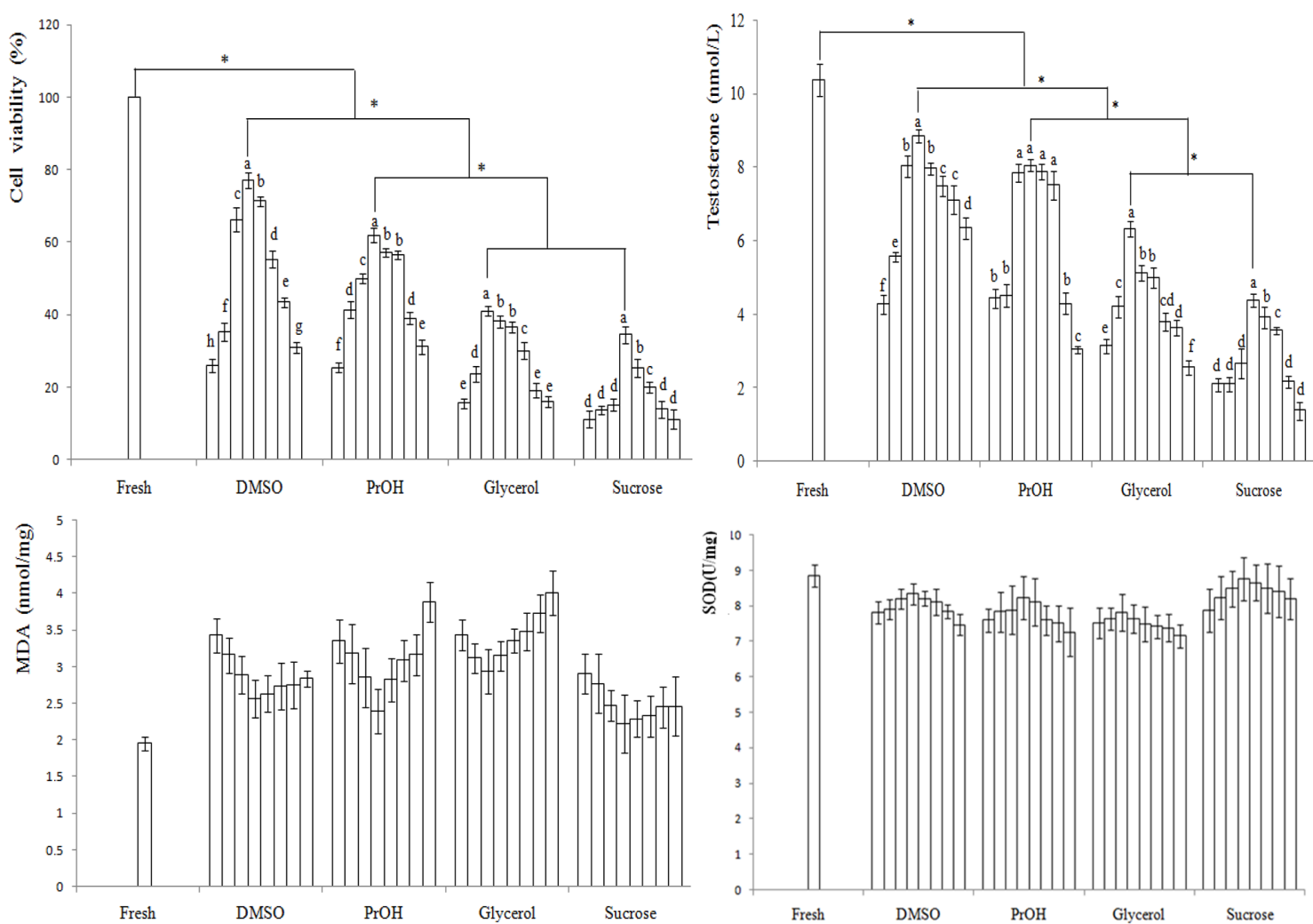

Figure 1. Cell viability, testosterone production, MDA, and SOD level in cryopreserved calf testis with different cryoprotectants. The concentration (abscissa) of each cryoprotectant increased from 2.5 to $20 \%$. All data are presented in mean percentage \pm SD; ${ }^{*} P<0.05$; DMSO: dimethyl sulfoxide; PrOH: propylene glycol.

higher concentrations of CPAs. The group treated with $10 \%$ DMSO showed higher cell viability and testosterone production than the groups treated with $10 \% \mathrm{PrOH}, 7.5 \%$ glycerol, and $10 \%$ sucrose $(P<0.05)$. The group treated with $10 \%$ $\mathrm{PrOH}$ had higher cell viability and testosterone production than the groups treated with $7.5 \%$ glycerol and $10 \%$ sucrose $(P<0.05)$. The group treated with $7.5 \%$ glycerol had higher cell viability and testosterone production than that treated with $10 \%$ sucrose. The group treated with $10 \%$ DMSO had higher cell viability and testosterone production than other freezing groups.

\subsection{The effect of different CPAs on MDA and SOD level}

The effects of the different concentrations and types of CPAs on MDA and SOD levels are shown in Fig. 1. After the cryopreservation of calf testicular tissue, the MDA level increased and the SOD level decreased compared with fresh testicular tissue, but there was no significant difference $(P>0.05)$. In each group of CPAs, the MDA level increased and the SOD level decreased at a lower concentration of CPAs, compared to CPAs at the optimal concentrations, as well as at higher concentrations of CPAs. But there was no significant differ-
Table 2. Correlations between cell viability, on the one hand, and testosterone production, MDA, and SOD level on the other.

\begin{tabular}{lllrr}
\hline & & Testosterone & MDA & SOD \\
\hline \multirow{2}{*}{ Cell viability } & $r$ & $0.939^{* *}$ & -0.203 & 0.149 \\
& $P$ value & 0.000 & 0.265 & 0.415 \\
\hline
\end{tabular}

Note: SOD - superoxide dismutase; MDA - malondialdehyde; ${ }^{* *} P<0.01$.

ence in MDA and SOD levels among different CPAs with various concentrations $(P>0.05)$.

\subsection{Correlation coefficient}

The relationship between cell viability, on the one hand, and testosterone production, SOD, and MDA levels on the other is shown in Table 2 . The cell viability was significantly positively correlated with testosterone production, and the Pearson correlation was $0.939(P<0.05)$. However, there was no significant correlation between cell viability and the level of SOD and MDA. 


\section{Discussion}

This study sought to research the effects of CPA types and concentration on calf testicular tissue during cryopreservation. In the process of cryopreservation, water molecules in the membrane surface and cytoplasmic matrix will be displaced by permeating CPAs, in order to avoid the formation of ice crystals that puncture the cell membrane structure. Nonpermeating CPAs can form a protection layer outside the cell membrane or use carbohydrates to displace the water molecules on the surface of the cell membrane to prevent ice crystal formation and cell membrane damage. DMSO, PrOH, glycerol, and permeating CPAs can protect the structure of the tissue by reducing the freezing point of water, promoting water vitrification, preventing the formation of ice crystals, and reducing the flow across the cell membrane (Fuller, 2004). Keros et al. (2005) compared the DMSO and sucrose regarding testicular tissue cryopreservation effects and showed that $10 \%$ DMSO could effectively keep the testicular tissue morphological structure and that $6 \%$ sucrose had the worst protection effect. With sucrose as CPA, testicular seminiferous tubule basal parts were seriously injured. DMSO had been found to be a more suitable CPA than ethylene glycol (EG) for immature mouse and rat testis tissue (Goossens et al., 2008; Jezek et al., 2001). Milazzo et al. (2008) reported that freezing testes with DMSO maintained not only immature testicular tissue architecture but also the viability of testicular cells. Travers et al. (2011) reported that using $1.5 \mathrm{M}$ DMSO as CPA had high cell viability in the cryopreservation of immature mouse testis tissue. Yildiz et al. (2013) reported that DMSO could effectively prevent the formation of ice crystals with a tetrahedral structure and provided a greater protection against freezing with regard to testicular survival rates in the grafted samples compared to PrOH, EG, and glycerol.

In this study, the optimal concentrations of DMSO, $\mathrm{PrOH}$, glycerol, and sucrose were 10, 10, 7.5, and $10 \%(P<0.05)$, respectively. The group treated with $10 \%$ DMSO had higher cell viability than the groups treated with $10 \% \mathrm{PrOH}, 7.5 \%$ glycerol, and $10 \%$ sucrose $(P<0.05)$. The group treated with $10 \% \mathrm{PrOH}$ had higher cell viability than the groups treated with $7.5 \%$ glycerol, and $10 \%$ sucrose $(P<0.05)$. The group treated with $7.5 \%$ glycerol had higher cell viability and testosterone production than that treated with $10 \%$ sucrose $(P<0.05)$. Our results agreed with previous reports that, compared with PrOH, glycerol and sucrose, DMSO provided the most protection. From the results it can be seen that the cell membrane permeability of DMSO is best. DMSO can maximize the replacement of water molecules in the cytoplasm, so the formation of ice crystal is difficult, and the cell membrane structure gets effective protection. In the freezing process glycerol and $\mathrm{PrOH}$ are not able to effectively displace the water molecules in cells, which form a number of ice crystals that destroy the cellular structure and cause cell death.
Testicular tissue is exposed to the air, causing oxidative stress, resulting in Leydig cell damage (Cao et al., 2004), and leading to the decrease in the synthesis and secretion of testosterone. After the cryopreservation of testicular tissue, detecting the content of testosterone can be used to evaluate of the survival of the tissue (Keros et al., 2007; Curaba et al., 2011; Gouk et al., 2011). Yildiz et al. (2013) reported that the DMSO group had similar serum testosterone levels to fresh grafted controls, while serum testosterone levels were significantly lower in the $\mathrm{PrOH}, \mathrm{EG}$, and glycerol groups. The results of previous studies, using DMSO for in vitro endocrine and partial exocrine functions in both human (Keros et al., 2005, 2007) and mouse immature testes (Milazzo et al., 2008), were similar to Yildiz et al. (2013). DMSO may electrostatically interact with membrane phospholipids to provide stabilization (Rudolph and Crowe, 1985; Anchordoguy et al., 1987). These results indicated that DMSO is the optimal CPA in testicular tissue cryopreservation, and the optimal concentration is $10 \%$. In this study, our result that the group treated with $10 \%$ DMSO had the highest testosterone production $(P<0.05)$ agreed with previous reports.

Besides the protective potential, CPAs may also have cytotoxicity. Tissue tolerance to CPAs is limited and overexposure may cause damage (Pegg, 2002). Unni et al. (2012) reported that the higher the DMSO concentrations, the greater the cytotoxicity. Pre-cryopreservation was carried out in immature rat tissue, and the cell death rate was as high as $45 \%$ when the concentration of DMSO was $2.5 \mathrm{M}$. After evaluation of the toxicity, the optimal concentration of DMSO was $1 \mathrm{M}$ during the immature rat testicular tissue cryopreservation (Unni et al., 2012). In addition, the higher the temperature, the higher the toxicity of DMSO. In the very low temperature, the cytotoxicity of DMSO is restrained. During thawing, with temperature increasing, the cytotoxicity of DMSO is increased, and thus the cell damage is increased. In this study, with optimal concentration of CPAs, the cell viability and testosterone decreased with the concentration increase $(P<0.05)$. This phenomenon may be associated with cytotoxicity. For example, when DMSO concentration is less than $10 \%$, DMSO cannot completely displace waters molecules in the testicular tissue cells, which can cause the formation of ice crystals and cell death. When DMSO concentration is greater than $10 \%$, the cytotoxicity of DMSO is stronger, resulting in cell death. When DMSO concentration is $10 \%$, DMSO evenly permeates the interior of testicular tissue, replacing the water molecules in the testicular tissue cells and making the formation of ice crystals difficult so as to protect the structure and function of the testis better. Glycerol molecular weight is more than that of DMSO, and its penetration speed is slower. In the process of thawing glycerol cannot seep from the cells quickly. When glycerol is left inside the cell, it can cause chromatin condensation at the periphery of the nucleus, mitochondrial expansion or interruption, and the loss of sertoli cells. When glycerol concentration is greater than $10 \%$, the amount of glycerol in the cell 
can cause the cytotoxicity of DMSO to act more strongly and cause cell damage.

Oxidative stress develops in association with an imbalance between reactive oxygen radicals (ROSs) and the antioxidant reserve system. ROSs are the product of normal cellular metabolism. Antioxidant defense mechanisms in the testis are important to protect sperm against ROS. Peroxidative damage is an important factor in sperm function impairment. As is well known, CPAs have different ways of protecting cells from freezing injuries (Honaramooz, 2012). Scavenging of oxygen free radicals and preventing oxidative stress to the cells (Fleck et al., 2000) seem to be important pathways. MDA is a marker of the level of lipid peroxidation (Vardi et al., 2009), and SOD is one of the major antioxidant enzymes that protect the male reproductive organs from the harmful effects of ROS (Fujii et al., 2003). SOD plays an important role in testicular development and spermatogenesis. Gale et al. (2014) reported that biomarkers of oxidative damage or changes in antioxidant metabolism may be useful indicators of the degree of cell damage occurring in oocytes at each stage of cryopreservation. In this study, the results showed that after the cryopreservation of calf testicular tissue, the MDA level increased and the SOD level decreased compared with fresh testicular tissue, but there was no significant difference $(P>0.05)$. These results indicated that CPAs had the ability to scavenge oxygen free radicals and prevent oxidative stress to the cells. When the optimal concentration of CPAs was achieved, the MDA level increased and the SOD level decreased with the concentration increase, but there were no significant differences $(P>0.05)$. This phenomenon may account for the toxicity of high-concentration CPAs, which could lead to decreased cell viability and result in the damage of the cellular antioxidant system and the metabolism.

The synthesis and secretion of testosterone have a close relationship with Leydig cells. When Leydig cells are damaged, testosterone levels drop. Some researchers consider it possible that after the cryopreservation of testicular tissue, the content of testosterone can be used to evaluate the survival of the tissue. In this study, the cell viability was significantly positively correlated with testosterone production $(P<0.05)$. The result indicated that the higher testosterone production, the higher cell viability. In this study, there was a negative correlation between cell viability and MDA level, while there was positive correlation between cell viability and SOD level, but neither was significant $(P>0.05)$. These results may be caused by the large concentration of the two enzymes or may be due to a number of factors affecting the evaluation of enzyme activity.

\section{Conclusions}

In conclusion, the cell viability and testosterone production varied among different CPAs with various concentrations. In cattle testicular tissue cryopreservation, compared to glyc- erol, PrOH, and sucrose, DMSO is the optimal cryoprotectant, and the optimal concentration is $10 \%$. In addition, the cell viability was significantly positively correlated with testosterone production $(P<0.05)$.

Acknowledgements. This research was supported by the Basic Scientific Research Expense of Sci-Tech Innovation Major Project of Northwest A\&F University (QN2011061).

Edited by: S. Maak

Reviewed by: X. Zhao and R. Pöhland

\section{References}

Abrishami, M., Anzar, M., Yang, Y., and Honaramooz, A.: Cryopreservation of immature porcine testis tissue to maintain its developmental potential after xenografting into recipient mice, Theriogenology, 73, 86-96, 2010.

Anchordoguy, T. J., Rudolph, A. S., Carpenter, J. F., and Crowe, J. H.: Modes of interaction of cryoprotectants with membrane phospholipids during freezing, Cryobiology, 24, 324-331, 1987.

Cao, L., Leers-Sucheta, S., and Azhar, S.: Aging alters the functional expression of enzymatic and nonenzymatic antioxidant defense systems in testicular rat Leydig cells, J. Steroid Biochem., 88, 61-67, 2004.

Chen, Y., Azad, M. B., and Gibson, S. B.: Superoxide is the major reactive oxygen species regulating autophagy, Cell Death Differ., 16, 1040-1052, 2009.

Curaba, M., Verleysen, M., Amorim, A. C., Dolmans, M. M., Van Langendonckt, A., Hovatta, O., Wyns, C., and Donnez, J.: Cryopreservation of prepubertal mouse testicular tissue by vitrification, Fertil. Steril., 95, 1229-1234, 2011.

Farias, J. G., Puebla, M., Acevedo, A., Tapia, P. J., Gutiérrez, E., Zepeda, A., Calaf, G., Juantok, C., and Reyes, J. G.: Oxidative stress in rat testis and epididymis under intermittent hypobaric hypoxia: protective role of ascorbate supplementation, J. Androl., 31, 314-321, 2010.

Fleck, R. A., Benson, E. E., Bremner, D. H., and Day, J. G.: Studies of free radical-mediated cryoinjury in the unicellular green alga Euglena gracilis using a non-destructive hydroxyl radical assay: a novel approach for developing protistan cryopreservation strategies, Free Radical Res., 32, 157-170, 2000.

Fujii, J., Iuchi, Y., Matsuki, S., and Ishii, T.: Cooperative function of antioxidant and redox systems against oxidative stress in male reproductive tissues, Asian J. Androl., 5, 231-242, 2003.

Fuller, B. J.: Cryoprotectants: the essential antifreezes to protect life in the frozen state, Cryoletters, 25, 375-388, 2004.

Gale, S. L., Burritt, D. J., Tervit, H. R., Adams, S. L., and McGowan, L. T.: An investigation of oxidative stress and antioxidant biomarkers during Greenshell mussel (Perna canaliculus) oocyte cryopreservation, Theriogenology, 82, 779-789, 2014.

Goossens, E., Frederickx, V., Geens, M., De Block, G., and Tournaye, H.: Cryosurvival and spermatogenesis after allografting prepubertal mouse tissue: comparison of two cryopreservation protocols, Fertil. Steril., 89, 725-727, 2008.

Gosden, R.: Cryopreservation: a cold look at technology for fertility preservation, Fertil. Steril., 96, 264-268, 2011. 
Gouk, S. S., Loh, Y. F. J., Kumar, S. D., Watson, P. F., and Kuleshova, L. L.: Cryopreservation of mouse testicular tissue: prospect for harvesting spermatogonial stem cells for fertility preservation, Fertil. Steril., 95, 2399-2403, 2011.

Honaramooz, A.: Cryopreservation of testicular tissue, in: Current Frontiers in Cryobiology, Agricultural and Biological Sciences, edited by: Katkov, I., InTech Press, Croatia, 209-228, 2012.

Hovatta, O.: Cryopreservation of testicular tissue in young cancer patients, Hum. Reprod. Update, 7, 378-383, 2001.

Jahnukainen, K., Ehmcke, J., Hergenrother, S. D., and Schlatt, S.: Effect of cold storage and cryopreservation of immature nonhuman primate testicular tissue on spermatogonial stem cell potential in xenografts, Hum. Reprod., 22, 1060-1067, 2007.

Jezek, D., Schulze, W., Kalanj-Bognar, S., Vukelic, Z., MilavecPuretic, V., and Krhen, I.: Effects of various cryopreservation media and freezing-thawing on the morphology of rat testicular biopsies, Andrologia, 33, 368-378, 2001.

Keros, V., Rosenlund, B., Hultenby, K., Aghajanova, L., Levkov, L., and Hovatta, O.: Optimizing cryopreservation of human testicular tissue: comparison of protocols with glycerol, propanediol and dimethylsulphoxide as cryoprotectants, Hum. Reprod., 20, 1676-1687, 2005.

Keros, V., Hultenby, K., Borgstrom, B., Fridstrom, M., Jahnukainen, K., and Hovattal, O.: Methods of cryopreservation of testicular tissue with viable spermatogonia in pre-pubertal boys undergoing gonadotoxic cancer treatment, Hum. Reprod., 22, 13841395, 2007.

Kishikawa, H., Tateno, H., and Yanagimachi, R.: Fertility of mouse spermatozoa retrieved from cadavers and maintained at 4 degrees C, J. Reprod. Fertil., 116, 217-222, 1999.

Martinez, A. F., Martinez-Pastor, F., Alvarez, M., FernandezSantos, M. R., Esteso, M. C., de Paz, P., Garde, J. J., and Anel, L.: Sperm parameters on Iberian red deer: Electroejaculation and post-mortem collection, Theriogenology, 70, 216-226, 2008.
Milazzo, J. P., Vaudreuil, L., Cauliez, B., Gruel, E., Masse, L., Mousset-Simeon, N., Mace, B., and Rives, N.: Comparison of conditions for cryopreservation of testicular tissue from immature mice, Hum. Reprod., 23, 17-28, 2008.

Pegg, D. E.: The history and principles of cryopreservation, Semin. Reprod. Med., 20, 5-13, 2002.

Rudolph, A. S. and Crowe, J. H.: Membrane Stabilization during Freezing - the Role of 2 Natural Cryoprotectants, Trehalose and Proline, Cryobiology, 22, 367-377, 1985.

Tatsumi, N., Fujisawa, M., Kanzaki, M., Okuda, Y., Okada, H., Arakawa, S., and Kamidono, S.: Nitric oxide production by cultured rat Leydig cells, Endocrinology, 138, 994-998, 1997.

Travers, A., Milazzo, J. P., Perdrix, A., Metton, C., Bironneau, A., Mace, B., and Rives, N.: Assessment of freezing procedures for rat immature testicular tissue, Theriogenology, 76, 981-990, 2011.

Unni, S., Kasiviswanathan, S., D’Souza, S., Khavale, S., Mukherjee, S., Patwardhan, S., and Bhartiya, D.: Efficient cryopreservation of testicular tissue: effect of age, sample state, and concentration of cryoprotectant, Fertil. Steril., 97, 200-208, 2012.

Vardi, N., Parlakpinar, H., Ates, B., Cetin, A., and Otlu, A.: Antiapoptotic and antioxidant effects of beta-carotene against methotrexate-induced testicular injury, Fertil. Steril., 92, 20282033, 2009.

Verheyen, G., Vernaeve, V., Van Landuyt, L., Tournaye, H., Devroey, P., and Van Steirteghem, A.: Should diagnostic testicular sperm retrieval followed by cryopreservation for later ICSI be the procedure of choice for all patients with non-obstructive azoospermia?, Hum. Reprod., 19, 2822-2830, 2004.

Yildiz, C., Mullen, B., Jarvi, K., McKerlie, C., and Lo, K. C.: Effect of different cryoprotectant gents on spermatogenesis efficiency in cryopreserved and grafted neonatal mouse testicular tissue, Cryobiology, 67, 70-75, 2013. 